\title{
DESENVOLVIMENTO DE UM MODELO DE SIMULAÇÃO PARA DIMENSIONAMENTO DE UM SISTEMA INTEGRADO PÁTIO-PORTO NA CADEIA DO MINÉRIO DE FERRO.
}

\author{
Engenharia de Sistemas Logísticos \\ Alexandre Font Julia - Escola Politécnica da USP - ajulia@samarco.com \\ Rui Carlos Botter - Escola Politécnica da USP - rcbotter@usp.br
}

\section{RESUMO}

No presente trabalho é proposto o desenvolvimento de um modelo de simulação para o dimensionamento de um sistema integrado pátio-porto aplicando o modelo em uma empresa do ramo de mineração. É feita uma revisão bibliográfica dos conceitos de simulação, dos elementos que compõem os sistemas de pátio e porto para produtos granéis, e de trabalhos relacionados ao tema. O trabalho apresenta uma análise entre possíveis cenários de expansão do sistema pátio-porto através de métricas definidas e faz uma comparação entre cada cenário proposto.

Palavras-chave: Simulação. Sistema integrado pátio-porto. Mineração.

\section{Introdução}

Atualmente, a expansão do comércio internacional está diretamente vinculada à atividade portuária, uma vez que grande parte das mercadorias que circulam pelo mundo são transportadas em navios e movimentadas pelos portos. No Brasil, mais de $90 \%$ das exportações são realizadas por meio dos terminais portuários (IBGE, 2009). Desta forma, no momento em que o Brasil procura consolidar a expansão de seu setor exportador, a modernização portuária adquire grande relevância (Portos do Brasil, 2009).

Mesmo considerando um cenário de retração da economia mundial, o Brasil tem oportunidade de expandir seus mercados pelo aumento na eficiência e redução de custos na logística de transporte, em especial nos portos, por onde escoam uma vasta gama de produtos, destacando-se os granéis sólidos, tais como: minério de ferro, carvão, soja, trigo, cimento, entre outras cargas.

Dentre os produtos citados acima, destaca-se o minério de ferro, objeto de estudo do presente trabalho, que representa cerca de 8\% (em US\$) das exportações brasileiras, e é responsável por aproximadamente 6\% do PIB Brasileiro (IBRAM, 2009) o que posiciona o Brasil como um dos maiores exportadores e produtores mundiais de minério de ferro. Segundo Alfredini (2005), em relação ao mercado transoceânico, o minério de ferro corresponde por aproximadamente $45 \%$ dos embarques de granéis sólidos.

O mercado mundial de minério de ferro envolve a produção e comercialização do minério de ferro nas seguintes modalidades: 
i. Na denominação genericamente conhecida como "finos de minério de ferro", que engloba os seguintes produtos: o "Pellet Screening" também chamado de "Sinter-feed", que nada mais é do que pelotas não conformes em relação ao diâmetro mínimo exigido pelos clientes, geralmente abaixo de $8 \mathrm{~mm}$. O "Pellet Screening" é empregado com abundância na fabricação de sínter para altosfornos. O outro produto é o "pellet feed" ou concentrado de minério de ferro, utilizado com restrições também na fabricação de sínter e, preferencialmente, como matéria-prima em pelotizadoras.

ii. "lump ore" ou minério granulado, normalmente peneirado e enfornado diretamente em reatores de redução, tais como altos-fornos e fornos de redução direta para a fabricação de ferro primário, respectivamente ferro-gusa e ferroesponja;

iii. "pellets" ou pelotas de minério de ferro, que de forma similar ao granulado é carregado diretamente em altos-fornos e processos de redução direta.

As pelotas de minério de ferro são formadas no processo de pelotização que é um processo de aglomeração de partículas ultrafinas de minério de ferro (abaixo de $0,15 \mathrm{~mm}$ ), através de um tratamento térmico. No cenário global de produção de aço, as pelotas são divididas em duas famílias, pelotas para Alto Forno, chamadas no presente trabalho de pelotas BF (Blast Furnance) e pelotas para Redução Direta, chamadas de pelotas DR (Direct Reduction).

A crescente demanda por minério de ferro, aliada aos sucessivos aumentos nos preços do produto, propiciou às empresas mineradoras realizarem investimentos em aumento de capacidade de produção e até mesmo aberturas de novas operações de mineração que antes eram economicamente inviáveis.

Tratando-se especificamente de projetos relacionados ao mercado transoceânico de minério de ferro, os investimentos em ampliação de portos e pátios de estocagem, incluindo máquinas móveis, correspondem a cerca de $5 \%$ do total do capital empregado, de maneira que o desenvolvimento de ferramentas de análise de cenários é indispensável como apoio à tomada de decisões e podem reduzir significativamente o desembolso, viabilizando o empreendimento em épocas de crise e propiciando uma operação eficiente e de baixo custo.

Geralmente, incrementos na eficiência das operações de estocagem e embarque podem ser conseguidos de quatro maneiras: repotenciamento de máquinas e equipamentos, aquisição de máquinas e equipamentos, mudanças de "layout" ou alteração no modo de operação.

Porém, uma análise integrada do sistema desde a estocagem dos produtos acabados em um local determinado até o seu carregamento nos navios, torna-se uma alternativa interessante para as empresas, permitindo uma avaliação mais ampla da operação, e será o objeto de pesquisa do presente trabalho, no qual será desenvolvida uma ferramenta de simulação para avaliar os reflexos da expansão da capacidade produtiva de uma empresa de mineração em seu pátio de estocagem e em seu sistema portuário, designado neste estudo como sistema "Pátio-Porto". 
A partir da literatura pesquisada, observa-se uma lacuna referente a modelos que integrem as duas operações logísticas (estocagem e embarque). Além disso, devido a essa carência de estudos que adotam modelos integrados, percebe-se a necessidade de definição de métricas de desempenho que considerem as interfaces entre as operações pátio e porto, o que também será tratado no presente trabalho.

\section{Pesquisa Bibliográfica}

A revisão bibliográfica de artigos, dissertações, periódicos e anais visa buscar trabalhos relacionados a sistemas portuários e pátios de estocagem, analisando as técnicas utilizadas pelos autores revisados a fim de elaborar um trabalho que contribua para o tema, além de buscar na literatura, quais os elementos que compõe o sistema pátio-porto.

O quadro a seguir apresenta um resumo dos trabalhos que utilizam a técnica de otimização.

\begin{tabular}{|c|c|c|c|c|c|}
\hline $\begin{array}{l}\text { Autor } \\
\text { (Ano) }\end{array}$ & $\begin{array}{c}\text { Área de } \\
\text { concentração }\end{array}$ & $\begin{array}{l}\text { Simulação / } \\
\text { Otimização }\end{array}$ & $\begin{array}{c}\text { alocação ótima de } \\
\text { produtos }\end{array}$ & roteirização & $\begin{array}{c}\text { dimensionamento } \\
\text { de frota }\end{array}$ \\
\hline $\begin{array}{l}\text { Bausch } \\
(1998)\end{array}$ & Porto & $\begin{array}{l}\text { Otimização / } \\
\text { Simulação }\end{array}$ & & $\mathrm{x}$ & \\
\hline $\begin{array}{l}\text { Fagerholt } \\
\text { (1999) }\end{array}$ & Porto & Otimização & & & $x$ \\
\hline $\begin{array}{l}\text { Molck } \\
(2002)\end{array}$ & Pátio & Otimização & $x$ & & \\
\hline $\begin{array}{l}\text { Rosa } \\
(2006)\end{array}$ & porto & Otimização & & $x$ & \\
\hline $\begin{array}{l}\text { Berger } \\
(2007)\end{array}$ & Pátio & Otimização & $x$ & & \\
\hline $\begin{array}{l}\text { Zhao } \\
(2007)\end{array}$ & pátio & Otimização & $\mathbf{x}$ & & \\
\hline
\end{tabular}

Quadro 1 - Trabalhos de otimização relacionados ao sistema pátio-porto

Dentre os trabalhos pesquisados que utilizam a técnica de otimização para estudar problemas relacionados ao sistema de pátios de estocagem percebe-se foco em resolver o problema de alocação ótima de produtos nos mesmos. Observando os trabalhos que abordam sistemas portuários, percebe-se que os autores buscam otimizar a roteirização dos navios e/ou dimensionar as frotas disponíveis para atender os navios no porto.

O quadro 2 mostra um quadro resumo dos trabalhos que utilizam a técnica de simulação para tratar problemas relacionados ao sistema pátio-porto. 


\begin{tabular}{|c|c|c|c|c|c|}
\hline $\begin{array}{l}\text { Autor } \\
\text { (Ano) }\end{array}$ & $\begin{array}{c}\text { Área de } \\
\text { concentração }\end{array}$ & layout & $\begin{array}{l}\text { dimensionamento } \\
\text { pátio / porto }\end{array}$ & roteirização & $\begin{array}{c}\text { Sequenciamento de } \\
\text { produçâao }\end{array}$ \\
\hline $\begin{array}{c}\text { Marasini } \\
(2000)\end{array}$ & pátio & $\mathrm{x}$ & & & \\
\hline $\begin{array}{l}\text { Fioroni } \\
\text { (2007) }\end{array}$ & Pátio & & $\mathrm{x}$ & & \\
\hline $\begin{array}{l}\text { Ono } \\
\text { (2007) }\end{array}$ & Pátio / Porto & & & $\mathrm{x}$ & $x$ \\
\hline $\begin{array}{l}\text { Fernandes } \\
\text { (2001) }\end{array}$ & Porto & & $x$ & & \\
\hline $\begin{array}{l}\text { Silva } \\
\text { (2005) }\end{array}$ & Porto & & $\mathrm{x}$ & & \\
\hline $\begin{array}{c}\text { Gonçalves } \\
(2008)\end{array}$ & Porto & & & $\mathrm{x}$ & \\
\hline $\begin{array}{l}\text { Bugaric } \\
(2007)\end{array}$ & Porto & & $x$ & & \\
\hline $\begin{array}{l}\text { Demirci } \\
\text { (2003) }\end{array}$ & Porto & & $\mathrm{x}$ & & \\
\hline
\end{tabular}

Quadro 2 - Trabalhos de simulação relacionados ao sistema pátio-porto

Os trabalhos que utilizam a técnica e simulação estão relacionados a problemas de dimensionamento do sistema, layout, roteirização e sequenciamento de produção.

Com isto, percebe-se que o uso de simulação para tratar problemas de dimensionamento de sistemas é mais adequado e por este motivo optou-se por tratar o problema através do uso de simulação, e esta técnica será aprofundada a seguir.

\section{Metodologia de Pesquisa}

No mundo cada vez mais competitivo, a simulação tornou-se uma ferramenta muito potente para o planejamento, projeto e controle de sistemas. Não sendo mais considerado como abordagem de "último recurso", é vista hoje como metodologia indispensável para solução de problemas de engenheiros, projetistas e administradores. Para auxiliar na elaboração de projetos de simulação existem diversas metodologias consagradas na literatura, dentre as quais podemos citar Banks (1984), Pedgen (1990) e Kelton Sadowski (1998). O uso de uma metodologia para execução do projeto de simulação permite evitar erros que podem causar o insucesso do modelo, tais como: definição equivocada dos objetivos do estudo da simulação, nível inadequado de detalhes, interpretações equivocadas da operação do sistema, falha na obtenção de dados representativos do comportamento do sistema, software de simulação inadequado, falha na consideração dos fatores aleatórios no comportamento do sistema simulado e utilização medidas de desempenho inadequadas.

Freitas (2001), baseado nos textos clássicos citados, propôs uma metodologia dividida em quatro etapas principais conforme figura 1 e que será utilizada na presente pesquisa. A escolha pela metodologia proposta por Freitas (2001), foi por possuir uma estrutura bem definida e consistente, além de ser de fácil implementação e análise de resultados. 


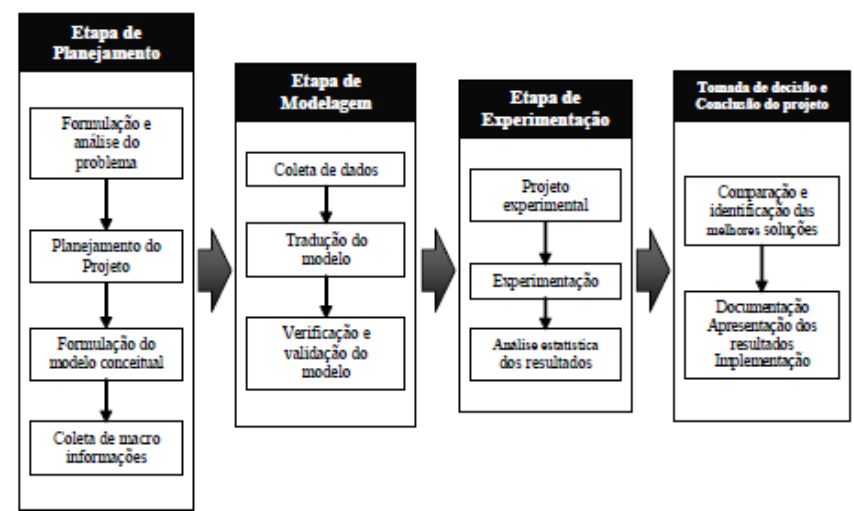

Figura 1 - Passos de um estudo de modelagem e simulação (Fonte: Freitas, 2001)

O software escolhido para desenvolver o modelo foi o ARENA, que é um ambiente gráfico integrado de simulação. O software ARENA foi considerado por renomados especialistas em simulação como "O mais inovador software de simulação", por unir os recursos de uma linguagem de simulação à facilidade de uso de um simulador, em um ambiente gráfico integrado. Não é necessário escrever nenhuma linha de código no software ARENA, pois todo o processo de criação do modelo de simulação é gráfico e visual.

\section{Caso Estudado}

O modelo de simulação a ser desenvolvido será baseado nas características e particularidades de uma empresa de mineração, a Samarco Mineração S/A, que tem suas operações de pátio e porto localizadas no Espírito Santo.

A empresa possui três usinas de pelotização com capacidade de produção anual de 22 milhões de toneladas de pelotas de Minério de Ferro, possuindo em seu portfólio de vendas um total de seis tipos de pelotas, divididas em duas famílias que são as pelotas BF e DR citadas na introdução. Além das pelotas, a empresa também produz 1 milhão de toneladas de outros dois produtos: o pellet screening e pellet feed, descritos na introdução.

A empresa deseja investir no aumento de sua capacidade de produção, passando para 34 milhões de toneladas sendo: 32 milhões de pelotas, 0,6 milhões de pellet screeening, e 1,4 milhões de pellet-feed. Com a configuração atual do sistema Pátio-Porto, estima-se que a empresa possui capacidade de embarcar 24 milhões de toneladas por ano. Esse aumento de capacidade de produção acarretará em investimentos nos pátios de estocagem e no sistema portuário. Tais investimentos serão analisados de forma integrada, de forma a proporcionar um aumento na capacidade de embarque com uma visão de todo o sistema e suas interferências. Isso porque as operações nos sistemas pátio de estocagem e porto consistem de interações complexas devido à possibilidade de utilização de múltiplos equipamentos (empilhadeiras, recuperadora, stack-reclaimer, correias transportadoras e shiploader), variações de taxas de embarque e estoques físicos finitos, influenciadas por um alto grau de variabilidade, introduzida na forma da disponibilidade de equipamentos, 
variações de produção, conflitos operacionais, atrasos na chegada de navios e atrasos operacionais.

Para um melhor entendimento dos processos da empresa estudada, a seguir serão descritos os sistemas de Pátio de Estocagem e do Porto,

\section{Pátio de Estocagem}

No sistema atual, a estocagem dos materiais produzidos pela empresa é feita em três pátios de estocagem, sendo que cada pátio é dividido em 120 balizas. Os três pátios da empresa são adjacentes e cercados por correias transportadoras, responsáveis por transportar o material das usinas para os pátios de estocagem e para o porto.

Os pátios de estocagem têm capacidade de estocar 1,8 milhões de toneladas aproximadamente. Sendo que o Pátio A possui uma capacidade de estocar aproximadamente 0,5 milhões de toneladas de minério. $O$ pátio $B$ tem capacidade de estocar 0,8 milhões de toneladas e o Pátio $C$ têm capacidade de estocar aproximadamente 0,5 milhões de toneladas de minério.

A operação de estocagem dos produtos nos mesmos é feita por uma série de equipamentos, destacados na figura a seguir:

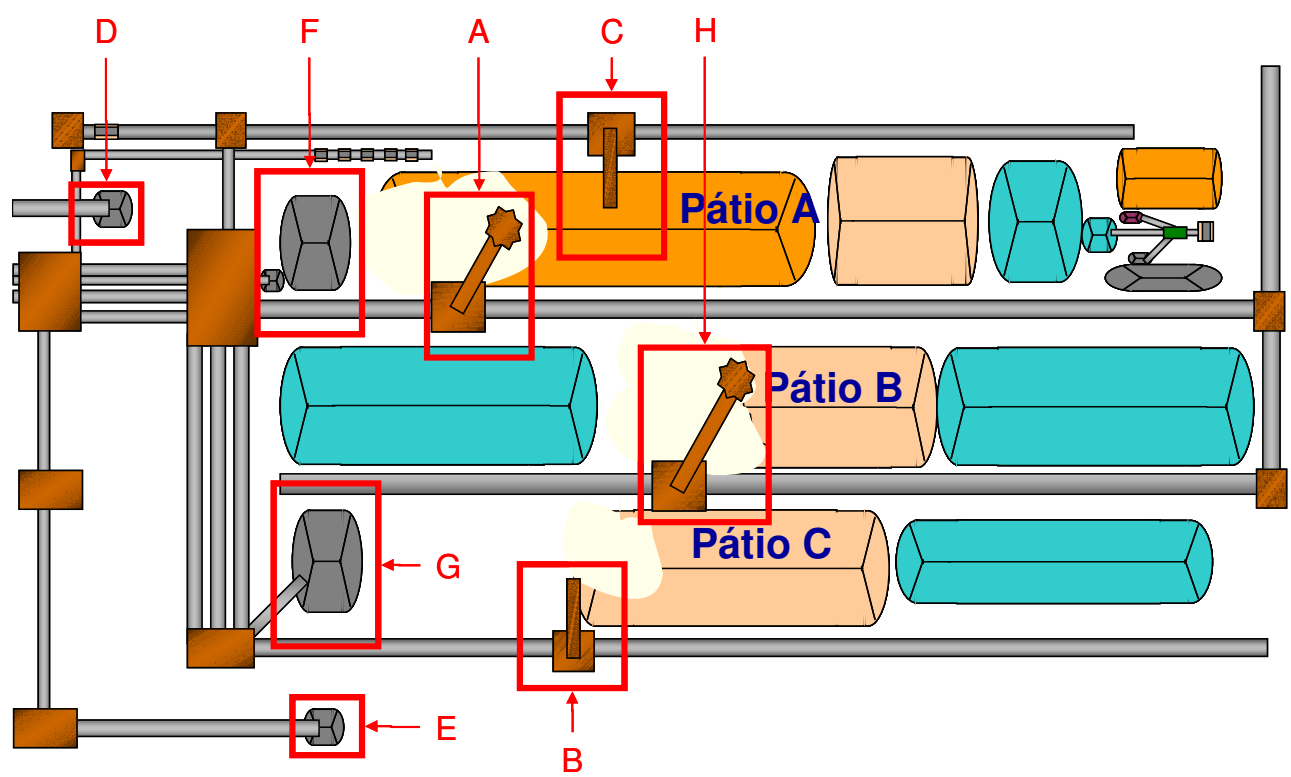

Figura 2 - Pátios de estocagem

A seguir, serão apresentados e descritos os equipamentos em destaque na figura 2:

A - Stack Reclaimer - Este equipamento empilha material nos pátios A e B.

B - Empilhadeira 2 - Este equipamento empilha material no pátio $\mathrm{C}$.

C - Empilhadeira 1 -Utilizada para empilhar material no pátio A.

D, E - Pilha de emergência das usinas 1 e 2 e Pilha de emergência da usina 3. 
F, G - Sistema de empilhamento de pellet Screening das usinas 1 e 2 e da Usina 3.

Cada tipo de produto segue uma regra para definição do local onde será estocada a produção, tais regras serão apresentadas a seguir:

\begin{tabular}{|c|c|c|c|c|}
\hline & \multicolumn{2}{|c|}{ Pelotas } & \multicolumn{2}{|c|}{ Pellet Feed } \\
\hline & Equipamento & Prioridade & Equipamento & Prioridade \\
\hline \multirow{2}{*}{ Pátio A } & Stack-Reclaimer & 3 & Empilhadeira 1 & 1 \\
\hline & ${ }^{*}$ Empilhadeira 1 & 4 & Stack-Reclaimer & 2 \\
\hline Pátio B & Stack-Reclaimer & 1 & Stack-Reclaimer & 4 \\
\hline Pátio C & Empilhadeira 2 & 2 & Empilhadeira 2 & 3 \\
\hline
\end{tabular}

Tabela 1 - Priorização do local e equipamento que fará o empilhamento

Da mesma forma, o sistema de recuperação do material dos pátios de estocagem possui regras de priorização conforme tabela abaixo:

\begin{tabular}{|c|c|c|}
\cline { 2 - 3 } \multicolumn{1}{c|}{} & \multicolumn{2}{|c|}{$\begin{array}{c}\text { Pelotas, Pellet Feed e Pellet } \\
\text { Screening }\end{array}$} \\
\cline { 2 - 3 } & Equipamento & Prioridade \\
\hline \multirow{2}{*}{ Pátio A } & Stack-Reclaimer & $\mathbf{4}$ \\
\hline \multirow{2}{*}{ Pátio B } & Stack-Reclaimer & $\mathbf{3}$ \\
\cline { 2 - 3 } & Retomadora & $\mathbf{1}$ \\
\hline \multirow{2}{*}{ Pátio C } & Retomadora & $\mathbf{2}$ \\
\hline
\end{tabular}

Tabela 2 - Priorização do pátio e do equipamento que fará a retirada do material do pátio

Após selecionar de qual pátio será retirado o material e qual o equipamento será utilizado inicia-se a recuperação do material do pátio para o navio.

\section{Sistema Portuário}

Toda a produção é escoada através de um porto que possui um píer de 313 metros de comprimento por 22 metros de largura e 2 berços de atracação protegidos por um quebra-mar em formato de L. O berço leste comporta navios de até 75.000 toneladas aproximadamente e o berço oeste comporta navios de até 200.000 toneladas aproximadamente.

Apesar de possuir dois berços o porto possui apenas uma linha de carregamento e apenas um equipamento capaz de transferir a produção das correias transportadoras para os navios, este equipamento é chamado de shiploader. 


\section{Discussão e Modelo} blocos:

O modelo de simulação desenvolvido pode ser dividido em 3(três) grandes

- A operação dos navios, que envolve o processo de: chegada de navios, escolha do berço onde cada navio deve atracar e desatracação dos navios.

- A operação de carregamento dos navios, que envolve as lógicas de qual equipamento será utilizado para carregar cada navio e de qual pátio deverá sair o material a ser embarcado.

- A operação de estocar material no pátio, que envolve as lógicas de escolha do pátio em que cada material deve ser estocado, qual equipamento será utilizado para estocar cada material, e o local do pátio escolhido onde o material deve ser estocado.

Para construção do modelo fez-se necessário um estudo de dados históricos do terminal portuário e do pátio de estocagem para determinar o comportamento de cada uma das variáveis de entrada do modelo. O período escolhido para análise foram os anos de 2006, 2007 e 2008, sendo que os dados analisados foram:

- Dados referentes à operação dos navios: loading rate; demurrage rate;turn time; tamanho de laydays; chegada dos navios em relação ao período de laydays; percentual de chegada de cada tipo de navio ao porto; tipo de produto que o navio irá carregar/descarregar; tempo de manobra de atracação; tempo de manobra de desatracação; condições meteorológicas adversas; necessidade de aguardar maré para desatracação;

- Dados referentes à operação de carregamento dos navios: tempo entre atracação e liberação; tempo entre liberação e início carregamento; disponibilidade da linha de carregamento; tempo intrínseco; tempo perdido; taxa efetiva; taxa global; tempo entre fim de carregamento e desatracação;

- Dados referentes ao empilhamento dos materiais nos pátios: volume de produção de pelotas de cada usina por hora; produção de pellet-feed por hora; disponibilidade dos equipamentos do pátio ( empilhadeira 1, empilhadeira 2, stack-reclaimer, retomadora)

A seguir uma tabela resumo dos dados de entrada utilizados no modelo: 


\begin{tabular}{|c|c|c|c|}
\hline & & & \\
\hline & & Valor & Unidade \\
\hline \multirow{12}{*}{ 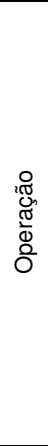 } & Loading rate navios Panamax & 40.000 & Toneladas/Dia \\
\hline & Loading rate navios Capesize & 60.000 & Toneladas/Dia \\
\hline & Demurrage rate & 20.000 & U\$/Dia \\
\hline & Turn time & 12 & Horas \\
\hline & Tamanho de Laydays & 10 & Dias \\
\hline & Chegada dos navios em relação ao período de Laydays & normal $(0.367,0.468)$ & Dias \\
\hline & Percentual de chegada de cada tipo de Navio ao porto & Tabela 6 & Toneladas \\
\hline & Tipo de produto que o navio irá carregar/descarregar & Gráfico 7 & - \\
\hline & Tempo de manobra de atracação & normal $(1.19,0.196)$ & Horas \\
\hline & Tempo de manobra de desatracação & $0.23+$ lognormal $(0.627,0.342)$ & Horas \\
\hline & Condições meteorológicas adversas & $\operatorname{normal}(6.13,1.98)$ & Horas \\
\hline & Necessidade de aguardar Maré para desatracação & $1.41+$ Lognormal $(2.83,1.46)$ & Horas \\
\hline \multirow{9}{*}{ 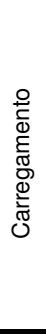 } & Tempo entre atracação e liberação & $-0.001+$ Lognormal $(0.382,0.363)$ & Horas \\
\hline & Tempo entre liberação e inicio carregamento & normal $(1.94,0.517)$ & Horas \\
\hline & Tempo de manutenção durante carregamento & $82 \%$ & $\%$ \\
\hline & Tempo intrínseco panamax & $26 \%$ & $\%$ \\
\hline & Tempo intrínseco capesize & $16 \%$ & $\%$ \\
\hline & Tempo perdido & $17 \%$ & $\%$ \\
\hline & Taxa efetiva panamax & normal $(4150,1280)$ & Toneladas/Hora \\
\hline & Taxa efetiva capesize & normal $(4790,1040)$ & Toneladas/Hora \\
\hline & Tempo entre fim de carregamento e desatracação & Lognormal $(2.92,2.21)$ & Horas \\
\hline \multirow{8}{*}{ 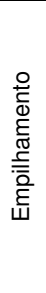 } & Produção de pelotas usina 1 & Normal $(817,33.6)$ & Toneladas/Hora \\
\hline & Produção de pelotas usina 2 & Normal $(857,40.9)$ & Toneladas/Hora \\
\hline & Produção de pelotas usina 3 & Normal $(862,45.8)$ & Toneladas/Hora \\
\hline & Produção de pellet-feed por hora & Normal $(2.550,752)$ & Toneladas/Dia \\
\hline & Disponibilidade da empilhadeira 1 & $92 \%$ & $\%$ \\
\hline & Disponibilidade da empilhadeira 2 & $92 \%$ & $\%$ \\
\hline & Disponibilidade da Stack-Reclaimer & $92 \%$ & $\%$ \\
\hline & Disponibilidade da retomadora & $92 \%$ & $\%$ \\
\hline
\end{tabular}

Tabela 3 - Dados de entrada do modelo

Para a validação, foram analisadas as principais saídas do modelo em comparação aos resultados reais do processo produtivo da Samarco Mineração S.A. referentes aos anos de 2006, 2007 e 2008.

\section{Cenários de Simulação}

Para todos os cenários foram rodadas 50 replicações de um ano e considerou-se o estoque inicial de 150.000 toneladas de pelotas BF, 150.000 toneladas de estoque DR, 50.000 de pellet feed e 50.000 de pellet screening, a distribuição de navios conforme realizado nos anos de 2006 a 2008 e a expansão do sistema produtivo da empresa conforme explicado anteriormente.

O quadro 3 resume os cenários a serem estudados: 


\begin{tabular}{|c|c|c|c|c|c|c|}
\hline & \multicolumn{5}{|c|}{ Pátio } \\
\hline & & Pátio Atual & $\begin{array}{l}\text { trocar Retomadora } \\
\text { por Stack reclaimer }\end{array}$ & $\begin{array}{c}\text { Trocar } \\
\text { Empilhadeira1 por } \\
\text { Stack Reclaimer }\end{array}$ & $\begin{array}{c}\text { Trocar } \\
\text { Empilhadeira2 por } \\
\text { Stack Reclaimer }\end{array}$ & $\begin{array}{c}\text { Adicionar } \\
\text { Retomadora na } \\
\text { linha da Stack } \\
\text { Reclaimer }\end{array}$ \\
\hline \multirow{6}{*}{ 움 } & Porto Atual & $1 \mathrm{~A}, 1 \mathrm{~B}$ e $1 \mathrm{C}$ & & & & \\
\hline & $\begin{array}{c}\text { Berço Leste para } \\
\text { navios de até } 200.000 \\
\text { ton. }\end{array}$ & $2 A$ e $2 B$ & & & & \\
\hline & $\begin{array}{c}\text { Adicionar Shiploader } \\
\text { no Pier atual }\end{array}$ & $3 A$ & $5 \mathrm{~A}$ & $6 \mathrm{~A}$ & $7 A$ & $8 \mathrm{~A}$ \\
\hline & \begin{tabular}{|} 
Berço Leste para \\
navios de até 200.000 \\
ton. e adicionar \\
Shiploader
\end{tabular} & 3B & 5B & $6 B$ & 7B & $8 B$ \\
\hline & $\begin{array}{c}\text { Novo pier com novo } \\
\text { sistema de embarque } \\
\text { para navios de até } \\
80.000 \text { ton. }\end{array}$ & $4 \mathrm{~A}$ & $9 A$ & $10 \mathrm{~A}$ & $11 \mathrm{~A}$ & $12 \mathrm{~A}$ \\
\hline & $\begin{array}{l}\text { Novo pier com novo } \\
\text { sistema de embarque } \\
\text { para navios de até } \\
200.000 \text { ton. }\end{array}$ & 4B & $9 B$ & $10 B$ & $11 \mathrm{~B}$ & $12 B$ \\
\hline
\end{tabular}

Quadro 3 - Cenários de simulação

A seguir serão apresentados todos os resultados dos cenários citados acima.

\section{Análise dos resultados}

A partir dos resultados gerados em cada cenário, é possível fazer uma análise geral das principais variáveis de saída do modelo, sendo elas: taxa de ocupação dos equipamentos de empilhamento e carregamento, taxa de ocupação dos berços, demurrage, tempo em fila e taxa global de carregamento. inferir que:

Em relação às taxas de ocupação, apresentadas no gráfico 01 abaixo, pode-se

- Em relação à ocupação dos berços, considerando os cenários de 3 a 12, onde é possível embarcar toda produção anual, observa-se que a ocupação média dos berços se mantém em torno de $90 \%$ para os cenários nos quais não é considerado um novo píer, com exceção do cenário 8 , que consegue reduzir a ocupação dos berços para $80 \%$, pois considera uma nova retomadora, o que aumenta significativamente a disponibilidade da linha de embarque. Para os cenários onde um novo píer é adicionado, a ocupação dos berços passa para $80 \%$, com exceção do cenário 4 , no qual não foi realizada nenhuma alteração no pátio. A análise integrada do sistema pátio-porto mostra que para diminuir a taxa de ocupação dos berços não necessariamente deve-se construir um novo píer, mas que o mesmo pode ser alcançado ao se aumentar as opções da linha de embarque (cenário 8). Por outro lado, caso não haja nenhuma modificação no pátio, os resultados não são satisfatórios, mesmo quando um novo píer é adicionado, o que indica que os cenários de 1 a 4 podem ser descartados. 
- O aumento das opções de empilhamento não gera ganhos significativos para o desempenho do sistema. Mesmo nos cenários que apresentaram as menores taxas de ocupação para estes equipamentos, não foi possível observar ganhos para o sistema. Dessa forma, identifica-se que o foco da análise deve ser nos cenários que relacionam maior disponibilidade da linha de embarque, descartando os cenários 5 e 9.

- Em relação à ocupação dos equipamentos da linha de embarque, percebe-se que as maiores reduções foram obtidas nos cenários 8 e 12, cenários nos quais foi adicionada uma nova retomadora na mesma linha da stack-reclaimer. Para os cenários 6,7, 10 e 11, mesmo aumentado-se as opções de recuperação de produtos dos pátios $\mathrm{A}$ e $\mathrm{C}$ através da modificação das empilhadeiras, observa-se redução de $5 \%$ na ocupação dos equipamentos da linha de embarque.

A análise descrita acima, permite inferir pelas taxas de ocupação, as opções que atendem o desempenho esperado do sistema são as propostas nos cenários 8 e 12.

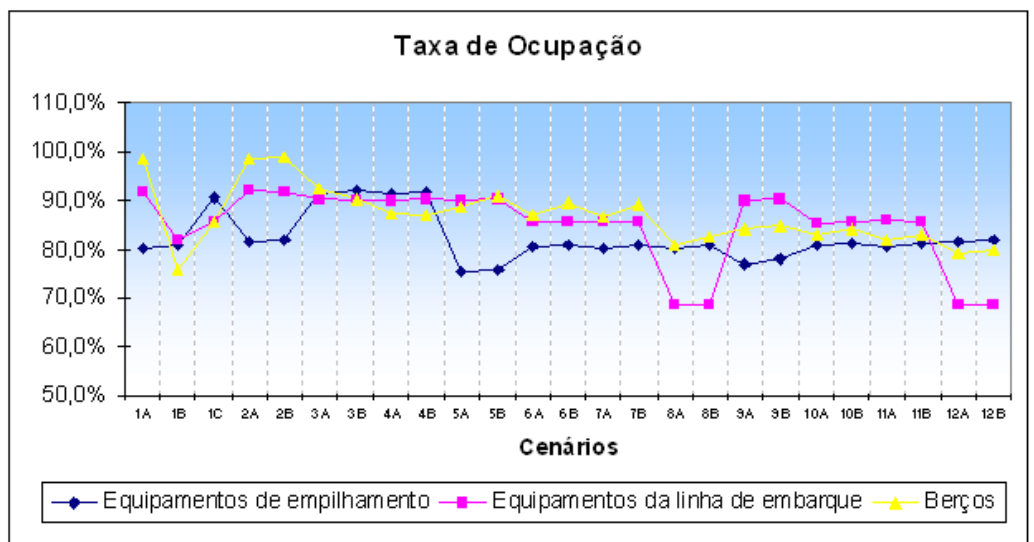

Gráfico 01 - Análise da ocupação dos berços, e dos equipamentos do pátio de cada cenário

Observando o gráfico 02 abaixo, contata-se a relação direta entre o demurrage e o tempo médio em fila, de modo que essas saídas serão analisadas em conjunto. Os cenários que apresentaram melhor desempenho são aqueles nos quais é adicionado um novo píer e mais uma opção de retomada de material, correspondendo aos cenários 10,11 e 12.

Uma observação importante é que ao se comparar a opção A com a opção B de cada cenário, na qual considera-se a retirada de restrição dos berços para navios de até 80.000 ton, percebe-se reduções da ordem de 6 a $8 \%$ para os cenários de 3 a 8 , onde não é adicionado um novo píer e para o cenário 9 onde é adicionado um novo píer mas não é adicionada mais uma opção de recuperação do material do pátio. Para os cenários onde é adicionado um novo píer e também é adicionada mais uma opção de retomada do material do pátio, cenários 10 a 12, a retirada desta restrição representa redução em torno de $35 \%$ nos valores de demurrage e tempo médio em filas. Sendo assim, a escolha de adequar os berços para recebimento de navios capesize dependerá do cenário a ser escolhido e também de uma análise para avaliar se as reduções obtidas compensam o investimento necessário para adequação do berço. $A$ definição do melhor cenário que atenda as condições de demurrage e tempo de espera 
também está relacionada ao nível de serviço que a empresa deseja prestar a seus clientes e ao montante que a empresa está disposta a desembolsar com o pagamento de demurrage ao longo dos anos.

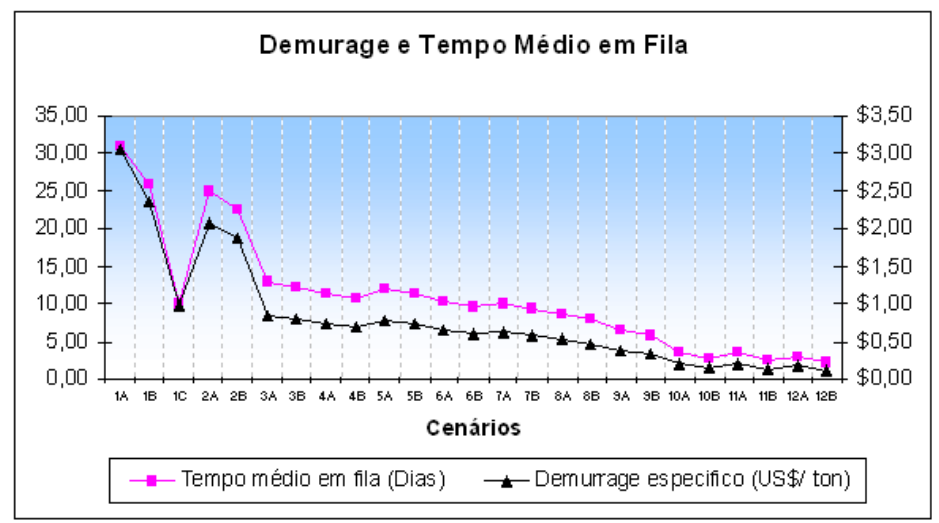

Gráfico 02 - Análise do demurrage e do tempo de espera de cada cenário

A última saída a ser analisada reflete diretamente a eficiência do sistema quanto ao carregamento dos navios. A taxa global de carregamento envolve os tempos parados durante o carregamento dos navios, por manutenção, tempos perdidos durante o carregamento, tempos intrínsecos e o tempo em que o navio esta sendo carregamento efetivamente. Quando o número de opções para realizar a operação de retomada do material dos pátios aumenta, a taxa global também aumenta. Neste sentido os cenários nos quais a taxa de carregamento aumenta são $6,7,8,10,11$ e 12, conforme o gráfico 03 abaixo.

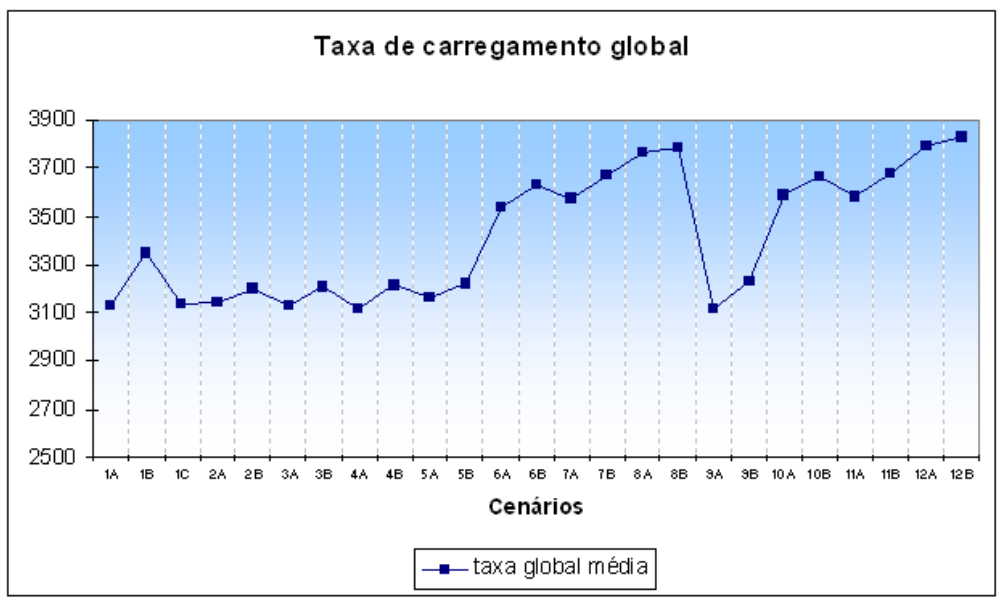

Gráfico 03 - Análise da taxa de carregamento global de cada cenário.

Para facilitar a definição da escolha do melhor cenário foi elaborado o quadro 4, apresentado a seguir. Apesar de a análise financeira não fazer parte do escopo do presente trabalho, a tabela apresenta uma coluna que tenta mostrar uma ordem de grandeza comparativa entre as configurações propostas, de forma que a escolha não seja apenas baseada nos resultados do simulador. Para os dados de saída do modelo, quanto maior o número de setas, significa melhor desempenho da variável de saída 
para o sistema. No caso do investimento, quanto maior o número de setas, menor será o investimento necessário.

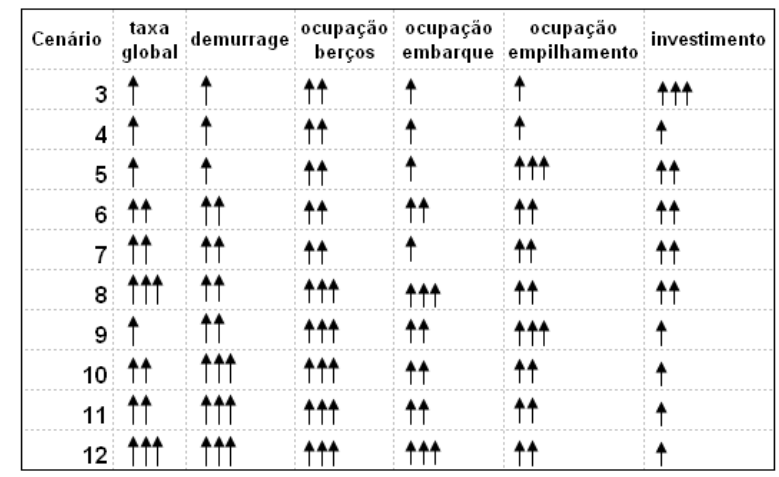

Quadro 4 - Comparação entre os cenários

Com os resultados obtidos acima é possível observar que o melhor cenário é o 12 que considera a construção de um novo píer com a inclusão de uma retomadora na mesma linha da atual stack reclaimer. Como estima-se que o investimento em um novo píer seja elevado, pode ser que essa situação seja economicamente inviável, de forma que o cenário 8 passa a apresentar os melhores resultados. Ainda em relação ao cenário 8, após estudos de engenharia pode ser constatado que não é possível adicionar o novo equipamento na mesma linha da stack reclaimer, seja por problemas de construtibilidade, interferências, riscos, etc. Nesse caso, então o melhor seria optar pelo cenário 11, no qual a empilhadeira 2 é substituída por uma stack-reclaimer além da construção do novo píer ou o cenário 7 , caso o píer não seja viável. Em relação à modificação de restrição dos berços, a decisão fica a cargo do cenário escolhido, conforme citado anteriormente. 


\section{Referências}

ALFREDINE, Paolo. Obras e gestão de portos e costas. Editora Edgard Blucher, Companhia Vale do Rio Doce. 2005.

BANKS, J.; CARSON, J.; NELSON, B. Discret-event System Simulation. New Jersey: Prentice Hall. 1996.

BAUSCH D. O. Scheduling short-term marine transport of bulk products - Maritime Policy \& Management - Online Publication Date: 01 Oct. 1998.

BERGER, Mariella. Aplicação da busca Tabu no gerenciamento de Pilhas em Pátios de Armazenamento de Placas de Aço. Universidade Federal do Espírito Santo, 2007

BUGARIC, U. Increasing the capacity of terminal for bulk cargo unloading, Faculty of Mechanical Engineering, University of Belgrade, Belgrade, Serbia, 2007.

DEMIRCI, E, SIMULATION; 79; 94; Simulation Modeling and Analysis of a Port Investment, /society for Modeling and Simulation International (SCS) 2003.

FAGERHOLT, K. Optimal fleet design in a ship routing problem - Department of Marine Systems Design, Norwegian University of Science and Technology, Trondheim, Norway - International Transactions in Operational Research 6. 1999. p. 453-464.

FERNANDES, Marcelo Gomes. Modelo econômico-operacional para análise e dimensionamento de terminais de contêineres e veículos - Departamento de Engenharia Naval e Oceânica da Escola Politécnica da Universidade de São Paulo, 2001.

FIORONI, Marcelo Moretti. Estudo estratégico de dimensionamento da infra-estrutura do pátio ferroviário de tubarão através de simulação, Escola Politécnica da USP, 2008.

FREITAS FILHO, P. J. Introdução à modelagem e simulação de sistemas. Florianópolis: Visual Books, 2001.

GONÇALVES, Gilmerson Inácio. Perspectivas de integração modal rodo-hidro-ferroviária na exportação de produtos agrícolas e minerais no estado de Mato Grosso do Sul - Departamento de Transportes da escola de engenharia de São Carlos, 2008

IBGE, Instituto Brasileiro de Geografia e Estatísticas - disponível em: <http://www.ibge.gov.br/home/>. Acesso em: Jan. 2009;

IBRAM, Instituto Brasileiro de Mineração. Disponível em: <http://www.ibram.org.br> Acesso em: Maio. 2009. 
KELTON, W. D. et al. Simulation with ARENA. 3. ed. New York: McGraw-Hill, 2002.

MARASINI, Ramesh. Stockyard layout planning in precast concrete products industry: a case study and proposed framework, Construction Management and Economics. 2001. 19, p. 365-377

MOLCK, Paulo Henrique Rodrigues. Métodos heuristicos em Programação de atividades em Pátios de Estocagem, Universidade Estadual de Campinas, 2002

ONO, Ricardo Terumichi. Modelagem sistêmica e Planejamento Logístico da cadeia de suprimentos de petróleo - Escola Politécnica da Universidade de São Paulo, 2007.

PEGDEN, C. D. et al. Introduction to simulation using SIMAN. 2nd ed. New York: McGraw-Hill, 1995.

Portos do Brasil, Disponível em: <www.portosdobrasil.gov.br> Acesso em: Abr. 2009.

ROSA, Rodrigo de Alvarenga. Uma abordagem baseada em negociação de agentes para a resolução do problema de alocação dinâmica de navios em berços de terminais Portuários - Universidade Federal do Espírito Santo, 2006.

SILVA, Vitor Borges. Distribuição modal rodo-ferroviária em uma rede de exportação de açucar a granel para o porto de Santos - Escola de Engenharia de São Carlos da Universidade de São Paulo, 2005.

ZHAO, Xiaobo. Storage-sapce capacitated inventory system with $(r, Q)$ Policies OPERATIONS RESEARCH, sep./oct 2007. vol. 55, ํ․ 5, p. 854-865. 